\title{
Evaluation of the Effectiveness of Innovative Management Projects in the Currency of the World
}

\author{
Sailau Baizakov ${ }^{1}$, Nauryz Baizakov² \\ ${ }^{1}$ Academic Supervisor of Economic Research Institute JSC, Doctor of Economics, Professor, Nur-Sultan, Kazakhstan \\ ${ }^{2}$ Senior Expert of Economic Research Institute JSC, Nur-Sultan, Kazakhstan \\ Email: *baizakov37@mail.ru
}

How to cite this paper: Baizakov, S. and Baizakov, N. (2019) Evaluation of the Effectiveness of Innovative Management Projects in the Currency of the World. American Journal of Industrial and Business Management, 9, 2008-2024.

https://doi.org/10.4236/ajibm.2019.911132

Received: October 26, 2018

Accepted: November 24, 2019

Published: November 27, 2019

Copyright $\odot 2019$ by author(s) and Scientific Research Publishing Inc. This work is licensed under the Creative Commons Attribution International License (CC BY 4.0).

http://creativecommons.org/licenses/by/4.0/

\begin{abstract}
The issues of algorithmization of achieving the sustainable development goals of economics of developing countries of the world are considered. The place of the S. Baizakov's model system is determined, which is compared to the FAO models for ensuring the productive safety of the world countries, proposed by the World Bank, as well as by the OECD management criteria system. This study was financially supported by grant No. AP05131044 from the scientific and technical programs and projects of the Ministry of Education and Science of the Republic of Kazakhstan.
\end{abstract}

\section{Keywords}

FAO Model, Sustainable Development Algorithm, Operator

\section{New Eco-Economic System of Commodity-Money Management}

Strategic planning of development of world's developing countries' market forces relies on the old interpretation of Direct Costing system. Thus, the process of determining net present value (NPV) is based on Direct Costing system, which was designated for accounting direct production expenditure by an American scholar D. Harris. According to this system, direct production expenditure is divided into fixed and variable.

In Kazakhstan, with the help of this system, fixed expenditure includes expenses related to administrative and management activities aimed at the sale of output products. Here, sale market research, commercial and general-administrative expenses are included. Variable expenditure includes expenses related to 
changes in the output production volume: materials, energy and fuel, salaries for employees and engineers.

As a result, the sum of direct and fixed costs represents the operating prime cost of the output. The amount of operating prime costs, depreciation of fixed assets of the enterprise, including taxes, determines the total prime cost of production.

As a result, the cash flow by enterprise development years is calculated according to the formula:

$$
\mathrm{NPV}=B-\left(3+\sum H+\sum K P\right)
$$

where $B$-revenue from the sale of commodity ore in the reference year.

3 -operating costs (fill prime cost) in the reference year.

$\sum H-$ tax amount paid in the reference year.

$\sum K P$-credit repayment amount in the reference year (including the interest on credit).

Hence, the net present value- $\mathrm{NPVO}_{(\ell)}$ is calculated according to the next formula:

$$
\mathrm{NPVO}_{(i)}=\frac{\mathrm{NPV}_{(i)}}{\left(1+И И_{1}\right) *\left(1+И И_{2}\right) *\left(1+И И_{3}\right) * \cdots *\left(1+И И_{\mathrm{H}+1}\right)}
$$

where: $\mathrm{NPV}_{(i)}$-cash flow of the reporting year $i$, million dollars.

ИИ

Finally, the present value, considering the discount coefficient, is calculated according to the formula:

$$
\begin{aligned}
\mathrm{NPV}_{i}= & \mathrm{NPVO}_{1} *(1+r)^{1}+\mathrm{NPVO}_{2} *(1+r)^{2}+\mathrm{NPVO}_{3} *(1+r)^{3} \\
& +\cdots+\mathrm{NPVO}_{n} *(1+r)^{n}
\end{aligned}
$$

where $r$-discount rate (money devaluation rate), indices $1,2,3, \cdots, n$-discount intervals: years, quarters, months, days.

At that time, accounting and analysis based on the Direct Costing system discovered great opportunities to set tight connections between production volume, gross and net profit, prime costs and gross revenues. They allowed to practically use it in the work of mathematical economists, production function methods, econometrics and regression analysis.

However, any initiative becomes "a dead dogma", if it does not continuously develop and does not find new arguments for the development of its viability. This point of view, focused on the continuous development of human capital, objectively determines the strict correspondence of the methods of market relations management with the level of development of labor and capital productive forces in the market-oriented economy of any country in the world.

Thus, in determining the break-even point of development according to the Direct Costing system, variable costs include salaries for workers and engineers, and fixed costs include salary costs for personnel employed in marketing, general and administrative divisions of an enterprise. It means that this system, which occurred in conditions of the 1940s of the last century, in conditions of tough competition between the economies of the Soviet Union and other developed 
countries of the world, did not take into account the development of human capital, hampered the opportunities for development of the working man himself, his creative, scientific and technological potential: the rich grew rich, the poor became poor.

In general, the Direct Costing system extremely limited the creative initiative of employees' participation in the production of goods and services, determining employment, income and pricing indicators by including in the fixed and variable costs of production, the remuneration of people employed in the economy of an enterprise.

However, the main drawback of this system was that it contradicted the macroeconomic approach of the quantitative theory of money, which governs the development of the market forces of the modern world economy and which corresponds to its globalization processes. There is an objective need to develop methods of management of the ecological and economic system of developing countries of the world, adequate to the current level of forces productivity development, which ensure the mutual correspondence of monetarism macroeconomic indicators with the microeconomic indicators of measuring the efficiency of the use of local ecological and economic resources.

In addition, the results of a scientific research of post-Harris period, especially related to the development of input output tables by: L. Kantorovich and T. Ch. Koopmans, awarded the Nobel Prize in 1975, as well as the fundamental work of Michael Porter "Competition" in 2001, allow to ensure such consistency and assess the competitiveness of firms and enterprises on the productivity of local environmental and economic resources. Both these works are unidirectional and are consistent with Milton Friedman's quantitative theory of money, and ensure that microeconomic indicators are comparable with macroeconomic indicators. Also, more works should be added: U. Nordhaus and P. Romer who made a step-back towards accounting of effectiveness of the use of local ecology and economy resources and initially evaluate the achievements of science ${ }^{1}$.

In recent years, thanks to initiatives of the Astana Economic Forum, largescale global research has been carried out in Kazakhstan. Among them, the work of S. Baizakov, Ye. Utembayev, N. Akimov, N. Sagadiyev, M. Amrenov, K. Berentayev is considered important. Their works are supported and responded by analysts from developed Western countries.

Ragnar Bentzel was right in his speech at the presentation of the works of Kantorovich and Koopmans, as a representative of the Royal Swedish Academy of Sciences noting the obviousness that "the main economic problems can be studied in a purely scientific sense, regardless of the political organization of the society in which they are studied".

In general, new horizons are opened up on the development of the scientific

${ }^{1}$ The Swedish Academy, in its message on the laureates, explains that U. Nordhaus and P. Romer created economic models which explain how the merket economy interacts with nature and knowledge. Thus, P. Romer in his worksn showed how knowledge could serve as an engine for long-term economic growth. While the works of U. Nordhaus describe interaction between society and nature. 
and technological base itself for recording and analyzing the levels of production, employment, incomes and prices, and thereby to fill the shortcomings of the Direct-Costing system in the development of human capital and the initiative of the busiest person in the economy. To this end, firstly, it is necessary to ensure that the methods of managing the development of human capital, as a key component of the development of the productive forces of developing countries of the world, are in line with the conditions for the development of human capital in the developed countries of the world.

Secondly, it is recommended to ensure that the objectives of operational planning are consistent with long-term sustainable development goals for a strategic perspective. Thirdly, identify key operators that allow integrating commodity and financial markets through the evolutionary development of Keynesian and monetarist theories.

Fourthly, develop a new multiplier for scientific and technological progress, ensuring the integration of capital development models in their commodity and monetary forms into the system of market relations.

\section{Setting the Task of Digitization of Sustainable Development Goals and the Main Operators of the Algorithm for Its Implementation}

At the last Astana Forum (Astana, June 2017), President of the state N. A. Nazarbayev stated the need for new methods for calculating indicators that measure the country's wealth and the well-being of citizens, as the frequently used indicator of GDP has a number of significant flaws. GDP does not reflect the long-term nature of economic activity, does not take into account damage to the environment, including the depletion of natural resources. In addition, it does not reflect the quality of life in a particular country, GDP per capita does not show the real well-being of citizens, does not consider the income stratification of the population. What I say is, the world community can adopt an updated methodology for calculating GDP on the basis of "green" GDP and such indices as the human development index, the OECD Better Life Index. It should adequately reflect the need for a balanced development of countries". Back in 2009, the President of the state wrote about this in the articles "Keys to the Crisis" and "The Fifth Way" [1] [2], and in his Address to the people of Kazakhstan in 2018, he indicated specific ways to implement his project on a new model of economic growth.

Algorithmization of the task of sustainable development of developing countries of the world at the Economic Research Institute is carried out by a limited number of operators, allowing to manage effectively the mutually agreed movements of indicators of economic and financial markets, up to the implementation of their goals.

Setting the task of achieving the sustainable development goals, and the operator tool for its algorithmization is aimed at implementing an equivalent transfer of national money of developing countries to their dollar equivalent, and use on a parity basis the whole arsenal of analysis and forecasting methodology devel- 
oped by international organizations, such as UN and OECD.

This formulation of the task and the chosen tool for its implementation, according to the developers, proceeds from the objective need to ensure parity of the national money of developing countries with the national currencies of developed countries that effectively interact with the world reserve currency, represented by the US dollar.

The main tool for solving this problem allows developing countries to ensure the commensurability of their money with their dollar equivalents. This ensures the alignment of the development methodology of the managerial economics of all countries of the world.

That is, each country on a parity basis can use innovative technologies proposed by international organizations and other tools for the effective and sustainable management of their country's economies and finances.

At the same time, a condition is created for the mutual coordination of the economic interests of local population, business and regions of each country based on the development of human capital and the effective use of local ecological and economic resources. In this case, the high rates of economic growth and the intended goals of increasing the well-being of citizens of country are ensured in the most efficient way.

\section{Composition and Content of Key Operators Integrating Product and Financial Markets through the Development of the Theories of Keynesianism and Monetarism}

The proposed operators are based on a qualitative theory of money developed by S. Baizakov [3]. This theory was built by the evolutionary development of economic laws, identified by supporters of the macroeconomic theory of J. Keynes [4] and the quantity theory of money of M. Friedman [5]. And the corresponding system of models of the qualitative theory of money is built on the basis of the conceptual idea of the President of Kazakhstan N.A. Nazarbayev, set out in "The Fifth Way".

The algorithm for solving the problem of the sustainable development of economies of developing countries ensures the commensurability of national money of developing countries of the world with the currencies of developed countries by establishing their true dollar equivalent. This algorithm consists of nine operators listed below; the description of the functions they perform in accordance with their economic purpose is also given there.

- Microeconomic operator for determining the multiplier of the productivity of resource costs at the enterprise level is $\mu=\mathrm{NGDP} / \mathrm{QP}$, where NGDP is nominal GDP, QP is the local ecological and economic resources consumed for the production of nominal GDP.

- Macroeconomic operator for determining the multiplier of scientific and technological progress at the country level is $c=\mu /(1+\mu)$.

- Macroeconomic operator for determining the GDP deflator (inflation mul- 
tiplier) $-p b$ according to the monetary policy methodology $-p b=\mathrm{NGDP} /$ RGDP, where RGDP is real GDP determined by the same monetarism methodology.

- Microeconomic operator for determining the value multiplier of the US dol$\operatorname{lar}(p p)$ as a reserve currency $-p p=\frac{c}{p b}$.

- Macroeconomic operator for determining the purchasing power of national money, which is expressed as a multiplier of the dollar equivalent of the aggregate of the true prices of goods and services of developing countries$p c=\frac{1}{p p}$.

- Intersectoral operator for determining the true price of each product or service in developing countries by calculating the savings in working time, which is determined by labor equivalents- $t_{p}$, the direct costs of local ecological and economic resources for producing a product $-i$, and labor equivalents $-T_{p}$ total production costs of the same product.

- Macroeconomic operator for determining the goods and services actually consumed in developing countries for consumption and accumulation in physical units calculated on the dollar equivalent of their money-FGDP $=c$ * RGDP, where according to the current monetarism model-RGDP $=$ $\mathrm{NGDP} / p b$.

- Macroeconomic operator for determining the goods and services actually consumed in developing countries for consumption and accumulation, calculated in national money of developing countries in their dollar equivalent-FGDP $=p p^{*}$ NGDP, where according to the current model of monetarismNGDP $=\frac{1}{p p} * M$-the mass of national money in circulation.

\section{System of Operators of Developing Countries as a Tool for Further Liberalization of the World Economy}

Based on the above system of operators, developing countries can fully establish the dollar equivalent of their money. As a result, they can apply the existing international experience and positive practices of other countries on a par with the developed countries in managing their economies.

Moreover, to analyze and forecast the development of developing countries, international organizations of the UN and the OECD countries use analogues to assess key indicators determined by the multipliers of scientific and technological progress and the productivity of local ecological and economic resources.

Thus, the first operator for determining the productivity of local ecological and economic resources was used by representatives of the UN's World Bank and consultants working in Kazakhstan through the TACIS of the Economic Commission for Europe in 1999-2004. The Ginsim models (United Kingdom) for analyzing the economics of enterprises were particularly valuable in Kazakhstan. 
The results of these works were published in Kazakhstan in 2002 under the scientific editorship of S. Baizakov, and are used in the practical work of the Economic Research Institute [6]. According to the results of research presented by Kateryna Schroeder (World Bank), the World Bank has been still using the multiplier of the productivity of local ecological and economic resources [7]. So, according to $\mathrm{K}$. Schroeder, this multiplier is developed in its original form, by assessing the effectiveness of domestic spending on the resources of developing countries in Central Asia when exporting agricultural products to China (DRC) [8]:

$$
\mathrm{DRC}_{i j}=\frac{c_{i j}^{d}}{p_{i j}-c_{i j}^{f}},
$$

where $c_{i j}^{d}$ and $c_{i j}^{f}$ represent, respectively, the domestic and foreign costs of input products " $i$ " in the country.

In case of export of meat, for example, from the countries of Central Asia to a specific country (China), if the multiplier $\mathrm{DRC}_{i j}<1$, this exporting country " $i$ " has a "comparative advantage" in the production of goods " $p$ " compared to China, that is, its goods (meat) cost less than the same goods in China (in the production for one dollar). Accordingly, the smaller the indicator $\mathrm{DRC}_{i j}$ in Central Asian countries, the greater will be the comparative advantage of these countries.

As can be seen, the constant for evaluating the efficiency of exports of developed countries is the dollar, not the dollar equivalent of national money of developing countries. In the economy of developing countries, not all goods and services have an export purpose. And not all of their goods, that are consumed domestically, are imported.

For example, the entire consumption fund and gross accumulation of these countries turn around by means of national money, that is the same goods as other goods: in our case, the tenge (not an international reserve currency) is itself a commodity. This means that national money of developing countries becomes lightly liquid commodities and determines the value of the nominal volume of production of the final product. This nominal volume is the nominal gross domestic product (NGDP) in the current prices of national money, determined in dollar terms.

At the same time, its physical volume, that is, the real volume of the final product, called the real gross domestic product (RGDP), is determined by means of the GDP deflator (inflation). According to world practice, in analyzing the development of economies of developing countries, World Bank experts use this indicator of real GDP (RGDP).

However, real GDP (RGDP) is not able to assess continuously the productivity of local ecological and economic resources used to produce nominal GDP (NGDP). Without such an assessment, as shown by the multiplier of K. Schroeder, a representative of the World Bank, it is not possible to determine the effectiveness or impact of any innovative solution.

So, the reciprocal of the multiplier of K. Schroeder, represents the value 
(productivity) of the country's local ecological and economic resources used to produce one-dollar equivalent of this commodity $\left(1 / \mathrm{DRC}_{i j}\right)$ :

$$
1 / \mathrm{DRC}_{i j}=\frac{p_{i j}-c_{i j}^{f}}{c_{i j}^{d}}=\frac{p_{i j}}{c_{i j}^{d}}-\frac{c_{i j}^{f}}{c_{i j}^{d}} .
$$

This indicator $1 / \mathrm{DRC}_{i j}$, is in fact an indicator " $\mu$ ”-that is, an indicator of the productivity of ecological and economic resources in the regions of this country. For this, it suffices, for example, to replace in the last multiplier $c_{i j}^{f}$ to $c_{i j}^{d}$. As a result of this replacement, you can get an analogue of the multiplier " $\mu$ " for any country in the world and conduct a comparative assessment of the effectiveness of its exports:

$$
\mu=\frac{p_{i j}-c_{i j}^{f}}{c_{i j}^{d}}=\frac{p_{i j}-c_{i j}^{d}}{c_{i j}^{d}}
$$

The above model of the multiplier of the UN representative K. Schroeder is a very valuable tool for analysis, as it expresses the production and economic relationship between producers of goods and ecological and economic factors of its production. The most important thing about it is that it reflects the relationship between microeconomic indicators with macroeconomic indicators.

Moreover, the model of this multiplier was used in assessing the comparative advantages of more than 30 commodity positions of enterprises in Kazakhstan. This work was done by the Kazakhstan group of experts under the methodological guidance of European expert Jean Michel, now an employee of the World Bank of the UN. The results of this work are also presented in the above book [[6], pp. 41-78].

Along with J. Michel, the methodological basis of S. Baizakov's model can be seen in the Ginsim model (UK), the software product of which was developed by the Maxwel Stamp company [ibid., pp. 111-144]. In particular, the nominal rate of protection (NRP), determined using both the Schroeder multiplier and the Ginsim project model, shows how much the price of local goods $(\mathrm{Pd})$ increases compared to the world price $(\mathrm{Pw})$ for the same product due to establishing customs duties [ibid, p. 133]:

$$
\mathrm{NRP}=[(\mathrm{Pd}-\mathrm{Pw}) / \mathrm{Pw}] * 100 .
$$

Despite the possibility of integrating microeconomic indicators with macroeconomic indicators, individual representatives of the World Bank, when analyzing the sustainability of transition countries, limit themselves to assessing the fall or growth of real GDP, despite the studies of their colleagues, in particular, $\mathrm{K}$. Schroeder on assessing the cost intensity of the obtained final product or the productivity of ecological and economic resources.

Thus, Table 1 shows a recent assessment of the level of development of the Kazakhstan's economy by the World Bank experts².

${ }^{2}$ Economic Report. Spring Edition 2017. World Bank Group, Global Practice on Macroeconomics and Fiscal Management. 
Table 1. Contribution to real GDP growth, 2013-2016 (in percentage points, unless otherwise indicated).

\begin{tabular}{ccccc}
\hline & 2013 & 2014 & 2015 & 2016 estimate \\
\hline Real GDP growth (in percent) & 6.0 & 4.2 & 1.2 & 1.0 \\
Domestic demand & 6.9 & 3.8 & 2.7 & 1.3 \\
Private consumption & 5.1 & 0.7 & 1.0 & -0.3 \\
Public consumption & 0.2 & 1.0 & 0.3 & 0.3 \\
Gross capital formation & 1.6 & 2.1 & 1.5 & 1.3 \\
Net export & -1.0 & 0.1 & -1.2 & -0.2 \\
Exports of goods and services & 1.1 & -1.1 & -1.2 & -1.0 \\
Imports of goods and services & -2.1 & 1.1 & 0.0 & 0.8 \\
Statistical discrepancy & 0.1 & 0.3 & -0.3 & -0.1 \\
\hline
\end{tabular}

Source: World Bank calculations based on the data published by the Committee on Statistics (Some figures may not be accurate due to rounding).

Table 1 reflects only the abstract contribution of all participants, first of all, the real and monetary and financial sectors of the economy of Kazakhstan, without detailing the contribution of each of them. That is, there is a need for such detail on the basis of identifying the causes. According to W. Leibniz, whose name was used in the name of famous institute of Hannover, "Reality can be understood for its reasons" Therefore, the establishment of causes will be the basis for making new managerial decisions that improve the "health" of the economy.

The second operator, according to Baizakov, seems to be a multiplier of scientific and technological progress, which is essentially macroeconomic, and by its nature, scientific and technological progress is the main engine of innovation in managing not only the development of the real and monetary and financial sectors, but also in the managerial economics sector (M. Bayeux).

In Western economic literature, the STP multiplier is known by the name "TFP" only as an indicator of the level of technological progress. According to K. Marx, "the first most important of the innate properties of matter is motion, not only as a mechanical and mathematical motion, but even more as aspiration, life spirit, tension or, using the expression of Jacob Boehme, suffering [Qual] of matter" [[7], p. 142].

The driving force, the vital spirit of economy is any desire of the three above-mentioned sectors of economy, which is called scientific and technological progress. However, the most common models of econometrics and production functions do not fully reflect the scientific and technological progress (STP).

Consequently, it is scientific and technological because the technology is being improved not only in the real sector of economy, but in all three managerial sectors: real, financial and managerial.

Research work is fruitful only if all three sectors of economy are armed with a clearly tested concept (idea) of sustainable development. According to the ten-year 
work of the Astana Economic Forum (AEF), such is, for example, the concept of "The Fifth Way" of the President of Kazakhstan N.A. Nazarbayev [1] [2].

In this context, Alisher Tleubayev, a doctoral candidate at the Leibniz Institute of Agricultural Development in Transition Economies (Germany), presented the denominator of the TFP model, not in the former two-factor form of the production function, but in a qualitatively new form, namely in the form of the STP multiplier [9]:

$$
\mathrm{TFP}=\frac{Y}{A(t) * K^{\alpha} * L^{\beta} * M^{\gamma}} .
$$

This multiplier of technological progress (in his other article, carried out jointly with one of the leaders of the same Leibniz Institute I. Bobojonov [10]), in fact, is the multiplier of scientific and technological progress, given in the second operator of the qualitative theory of money of S. Baizakov.

Now the multiplier of scientific and technological progress, which is supported by such an authoritative institute named after W. Leibniz (represented by the TFP model in the interpretation of Tleubayev-Bobojonov), confirms the emergence of S. Baizakov's new qualitative theory of money. In fact, this new qualitative theory of money has been developed through the evolutionary development of the quantitative theory of money of M. Friedman, that is, by complementing it, but not denying it.

Thus, in calculations and theoretical studies of Bobojonov and Tleubayev, the numerator of the TFP technological progress indicator is expressed by the " $Y$ " indicator, which is the nominal GDP of the second Baizakov operator $(Y=$ NGDP), and the denominator of the TFP indicator is determined not by two, but by a three-factor production function in the approach of Bobojonov-Tleubayev. In this case, the information base for the forecast of the TFP indicator itself is the dynamics of the relationship of the final product $-Y$ to the total costs of ecological and economic resources $-X$, the integrator of three factors ( $L$-labor, $K$-capital and $M^{Y}$-current costs of local ecological and economic resources).

In general, the TFP technological progress indicator can be predicted based on the release of the system of national accounts. Respectively, parameters $\alpha, \beta$ and $\gamma$ represent the elasticities of the above three factors.

Thus, the Bobojonov-Tleubayev's model can be used in predicting the system of the UN sustainable development goals. The advantage of their model is that technological progress is expressed by the production attitude not of two factors, but of three factors: labor, capital and natural matter. Due to the lack of such a three-factor approach, which is systemic, Kazakhstan and other developing countries suffer a shortage of analytical and forecasting tools for long-term forecasting.

As far as short-term forecasting is concerned, the Kazakhstan's interpretation of the multipliers of scientific and technological progress was previously described in the article by Baizakov and Shuneyev (2014) in [11]. Unlike the multiplier TFP, the Baizakov-Shuneyev's forecast model (2014) is designed for 
short-term planning of up to three-five years, and it is also implemented according to the reporting data of the statistical authorities of each country. Therefore, for the model of forecasting the economy for the long-term perspective up to 2025-2050, it is proposed, mainly, to be based on the dynamics of the STP multiplier and other related progress multipliers.

In general, this Baizakov-Shuneyev's forecast model, as well as S. Baizakov's multiplier of scientific and technological progress, are being developed in the name of the Bobojonov-Tleubayev's (Germany) long-term model and other models of developed countries and international organizations such as the human development index and OECD indicators.

\section{STP Multiplier Is the Key to Integrating the Development Patterns of Capital in Their Commodity and Money Forms into a System of Market Relations}

As you know, according the definition of the value of a dollar using a macroeconomic textbook (reprinted in Russia more than 13 times), "value of money is the amount of goods and services that can be exchanged per unit of money (dollar); and the purchasing power of a monetary unit is the reciprocal of the price level" [12].

This means that the purchasing power of the US dollar $(p p)$, as the price of the reserve currency is determined by the formula:

$$
p p=\frac{c}{p b},
$$

where $p b$ is the growth rate of the GDP deflator, $c$ is the growth rate of the multiplier of scientific and technological progress.

This relation shows that the growth rate of the GDP deflator is decomposed into two indicators:

$$
p b=\frac{c}{p p}=c * p c,
$$

This implies:

$$
p c=\frac{1}{p p},
$$

where $p c$ is the true price of national money in circulation, the market price of which is determined in the currency market of each country $(M)$.

But how is the money supply in circulation determined? So, according to the basic economic law of the quantity theory of money, the following equality takes place:

$$
v=\mathrm{NGDP} / M,
$$

where $v$ is the velocity of money circulation according to the quantity theory of money.

According to the basic law of the qualitative theory of money, not only the cost of nominal GDP (NGDP) is circulated, but also the cost of the volume of 
total costs for its production $(X)$ :

$$
v_{x}=X / M
$$

where $V_{X}$ is the velocity of money circulation according to the qualitative theory of money.

This implies that the velocity of money circulation according to the quantity theory of money is connected with the velocity of money circulation according to the qualitative theory of money [13]:

$$
v=\mathrm{NGDP} / M=\mu /(1+\mu) * X / M=c * v_{x},
$$

where $\mu /(1+\mu)=c$ is the multiplier of scientific and technological progress, and " $V_{x}$ " is the multiplier of the total costs of producing nominal GDP.

Since $v=c * v_{x}$, the money supply- $M$ is determined by the formula:

$$
\mathrm{NGDP}=\left(c * v_{x}\right) * M
$$

where $p c=1 / p p=\left(c * v_{x}\right)$ is the true price of deficiency of the dollar equivalent of national money, as a liquid commodity, in relation to reserve currencies.

That is, in case of Kazakhstan, the policy of the National Bank should not focus on inflation targeting, but on reducing the deficit of the money supply in circulation. It is this multiplier " $c * v_{x}$ ” that should become a guideline for setting the discount rate of the Central Banks of developing countries of the world.

As a result, nominal GDP in current national money will grow indefinitely, and the national money itself will depreciate indefinitely.

This conclusion in relation to Kazakhstan, as an intensively developing country, with the intention to enter the 30 best countries in the world, according to its economic development, makes it possible to argue that the current focus on the nominal GDP indicator is necessary but not sufficient. And, therefore, relying directly on the real GDP indicator obtained from it distorts the true rates of economic growth.

The World Bank report (2017) mentions that the development of the political system of Kazakhstan indicates the transfer of activity on economic policy management from the Administration of President to the structures of the Government and Parliament and the expansion of powers of local executive bodies. Kazakhstan has announced an increase in the competitiveness of the economy Modernization 3.0 and the implementation of five priorities for technical modernization, the business environment, macroeconomic stability, improving the quality of human capital, strengthening security institutions and measures to combat corruption.

However, the implementation of the Superprogram of Modernization and the five priorities faced an imbalance on the part of the readiness of state (heads of the economic bloc of the government, the National Bank) and market institutions to synchronize their actions with the problem of human capital development.

This imbalance led to a rather unexpected for outsiders' view, but an absolutely adequate response on the part of the authorities to the demands of society, namely focusing on one of the five priorities - the development of human capi- 
tal. This was announced by the President of the state this year, noting the need to implement the Five Social Presidential Initiatives (mortgage "7-20-25", student housing, etc.).

At the same time, it should be assumed that the potential of these five initiatives will be difficult to assess and maximize in all spheres of the country's activities without an appropriate methodology. Such a methodology should be based both on the existing traditional indicators and on the new three multipliers associated with the implementation of science and technology in the life of every citizen of the country. As a result, they are aimed at improving well-being by increasing human capital and harmonizing relations in the three chains "manscience" (STP/TFP multiplier), "man-man" (multiplier of socio-economic progress), as well as "man-society" (multiplier of socio-political progress).

\section{Experimental Calculations for the Analysis of the Comparative Effectiveness of Innovative Projects}

\subsection{Initial Conditions of the Comparative Analysis}

The initial base was the information of the consolidated balance of Sokolov-Sarybai Mining Production Association (SSGPO) for 2016, as a conditional example for carrying out experimental calculations. It is supplemented with a forecast for 2017 and an expected estimate of data for 2018. For the forecast of development of SSGPO for 2019-2030, a database of project data for its operational and investment development, exclusively defined in conventional numbers, was used. Consequently, the analysis presented below has only an experimental character for testing the algorithm for solving the problem according to the S. Baizakov's model [14] [15].

\subsection{The Analysis Was Carried Out by Identifying the Causes of Risks and Risk Management in the Real Sector}

The level of innovativeness of the technology in each option of the real sector is determined by the productivity of the costs of current material resources (which are used to produce the final product). And the function of scientific and technological progress is defined as the result of the productivity of material resources [15].

Thus, Table 2 shows the design scheme for determining the function of scientific and technological progress of one of two options by year of the analytical period, where its last columns express the indicators of the second option for 2018 (expect.) and 2028 (forecast). According to a given database of design data, the Baizakov's calculation work algorithm is able to assess any prevailing macroeconomic or microeconomic situation.

\subsection{Analysis of the Innovativeness of Projects (and Operational Plans) in the Financial Sector and Assessment of Cost-Effectiveness of Their Implementation}

The analysis was performed by identifying the causes, as sources of risk and risk 
management in the financial sector of the economy. The innovativeness of technology in the economy of the financial sector is determined by the productivity of investment costs and the development of human capital (TW) in the form of normal profits (TR).

As you know, the normal profit is determined relative to the payroll, and it serves as one of the main sources of savings and, consequently, gross accumulation. In a civilized world focused on the development of human capital, the spiritual and creative potential of the person himself, all other conditions being the same, the level of the human development index should constantly increase and, at least, should not decrease.

In general, the function of socio-economic progress is defined as the result of the productivity of expenses for normal profit, defined as an indicator of rational savings. Thus, Table 3 shows the calculated scheme for determining the function of socio-economic progress over the years of the analytical period in our illustrative

Table 2. Evaluation of the effectiveness of scientific and technological cooperation.

\begin{tabular}{|c|c|c|c|c|}
\hline Algorithm & Name of indicators & Unit of meas. & 2016 (actual) & 2028 (forecast) \\
\hline $\mathrm{NX}=\mathrm{NGDP}+\mathrm{QP}$ & $\begin{array}{l}\text { Scientific and technological potential of SSGPO in terms } \\
\text { of value }\end{array}$ & thousand KZT & $183,963,219.00$ & $302,054,905.91$ \\
\hline$\mu=\mathrm{NGDP} / \mathrm{QP}$ & Efficiency of variable costs excluding salary components & $\mathrm{KZT} / \mathrm{KZT}$ & 2.85 & 0.98 \\
\hline \multirow[t]{2}{*}{$c=\mathrm{NGDP} / \mathrm{NX}=\mu /(1+\mu)$} & $\begin{array}{l}\text { Multiplier of scientific and technological progress on the } \\
\text { productivity of variable costs excluding salary }\end{array}$ & $\mathrm{KZT} / \mathrm{KZT}$ & 0.74 & 0.49 \\
\hline & The same in percent & $\%$ & 100.00 & 66.74 \\
\hline $\mathrm{NGDP}=\mu /(1+\mu) * \mathrm{NX}$ & $\begin{array}{l}\text { Algorithm for calculating the STP multiplier: } 1 \% \mathrm{NX} \\
\text { provides } \mu /(1+\mu) \% \text { NGDP }\end{array}$ & thousand KZT & $136,140,105.90$ & $149,191,474.19$ \\
\hline $\mathrm{NX}=\mathrm{TW}+\mathrm{TR}+\mathrm{QP}$ & $\begin{array}{l}\text { Total consumption of resources for the production of } \\
\text { rational consumption in SSGPO }\end{array}$ & thousand KZT & $183,963,219.00$ & $302,054,905.91$ \\
\hline $\mathrm{NGDP}=\mathrm{TW}+\mathrm{TR}$ & $\begin{array}{l}\text { NGDP-GVA SSGPO, analogue of the nominal GDP of } \\
\text { the country }\end{array}$ & thousand KZT & $136,140,105.90$ & $149,191,474.19$ \\
\hline $\mathrm{NGDP}=\mu * \mathrm{QP}$ & $\begin{array}{l}\text { NGDP-GVA SSGPO, analogue of the nominal GDP of } \\
\text { the country }\end{array}$ & thousand KZT & $136,140,105.90$ & $149,191,474.19$ \\
\hline $\mathrm{NGDP}=\mu /(1+\mu) * \mathrm{NX}$ & $\begin{array}{l}\text { NGDP-GVA SSGPO, analogue of the nominal GDP of } \\
\text { the country }\end{array}$ & thousand KZT & $136,140,105.90$ & $149,191,474.19$ \\
\hline
\end{tabular}

Table 3. Assessment of the effectiveness of socio-economic potential.

\begin{tabular}{clccc}
\hline Algorithm & \multicolumn{1}{c}{ Name of indicators } & Unit of meas. & 2016 (actual) & 2028 (forecast) \\
\hline$\eta=\mathrm{TW} / \mathrm{TR}$ & $\begin{array}{l}\text { Efficiency of expenses in SSGPO for normal profit in the } \\
\text { short-term period }\end{array}$ & KZT/KZT & 0.39 & 0.23 \\
$q=\eta /(1+\eta)$ & Multiplier of socio-economic progress in SSGPO, & KZT/KZT & 0.28 & 0.19 \\
$q=\eta /(1+\eta)$ & The same in percent & $\%$ & 100.00 & 67.33 \\
$\mathrm{TW}=\eta /(1+\eta) * \mathrm{NGDP}$ & $\begin{array}{l}\text { Algorithm for calculating the effect of the multiplier of } \\
\text { socio-economic progress in SSGPO } \\
\text { Average annual labor productivity per worker in SSGPO }\end{array}$ & thousand KZT & $38,044,699.70$ & $28,070,475.55$ \\
NGDP/L $=\varphi$ & thousand KZT & 7318.97 & $11,387.79$ \\
\hline
\end{tabular}


example, in SSGPO, where the last columns express changes in the indicators for 2018-2028 according to the same option 2. Table 2 and Table 3 were compiled according to the method of determining the multiplier of S. Baizakov, and the sources of the used data are the same.

\subsection{Analysis and Assessment of Socio-Political Progress in the Development of the Managerial Economics Sector}

The innovation of technology in the managerial economics sector is determined by the product of the multipliers of scientific and technological progress and socio-economic progress $\left(c^{\star} q\right)$. Innovation, in this case, means both the novation itself, the innovation, and the process, that is, the potential capable of introducing something new in the economics of the real, financial and managerial sectors, spiritually enriched with the desire of progress not only of a human-entrepreneur, but also a simple worker.

But as a potential, not every innovation contributes to the efficiency of production of goods and services, which are currently in demand and are supplied by demand from consumers.

That is, innovation does not necessarily provide a comparative or absolute increase in the efficiency of production of the final results of intellectual activity, its imagination, creative process, discoveries, inventions and rationalization. The fruit of this aspiration of a person of labor and management is the synergistic effect associated with the productivity of the local ecological and economic resources of the country and the multiplier of scientific and technological progress, determined on its basis.

But the socio-political progress in the development of the managerial economics sector is not only linked to the harmonization of the development of commodity and financial capital. It is also linked to the development of the main component of the development of the productive forces of the country, the spiritual and material development of its human potential. Such a three-tier system means that the corresponding function of socio-political progress is harmonized with scientific, technological and socio-economic progress. Thus, the following table shows the calculated scheme for determining the function of socio-political progress over the years of the analytical period, and the last columns express the indicators for the years 2016-1028. Table 3 and Table 4 were compiled using the algorithm for determining the multiplier of S. Baizakov, on the basis of the previous information of option 2 .

\subsection{Comparative Analysis of Two Project Options for Innovative Development of SSGPO (with All Other Conditions Being the Same)}

Table 5 of the comparative analysis shows that the Baizakov's model is not aimed at increasing the money capital, which, unfortunately, is happening now in Kazakhstan. But it is aimed at the development of human capital, which is the most important of the tasks of the well-being of humanity, which is confirmed 
Table 4. Assessment of the effectiveness of socio-political potential.

\begin{tabular}{|c|c|c|c|c|}
\hline Algorithm & Name of indicators & Unit of meas. & 2016 (actual) & 2028 (forecast) \\
\hline $\mathrm{TW} / \mathrm{L}=w$ & Basic level of the average annual salary per worker in SSGPO & thousand KZT & 2045.30 & 2142.62 \\
\hline $\mathrm{NGDP} / \mathrm{L}=\varphi$ & Basic average annual labor productivity per worker in SSGPO & thousand KZT & 7318.97 & $11,387.79$ \\
\hline$w=\mu /(1+\mu) * \eta /(1+\eta) * \psi$ & $\begin{array}{l}\text { Basic level of average annual wage per one worker at full costs } \\
\text { in SSGPO }\end{array}$ & thousand KZT & 2045.30 & 2142.62 \\
\hline$\psi$ & $\begin{array}{l}\text { Basic annual average labor productivity at full cost, per } \\
\text { worker in SSGPO }\end{array}$ & thousand KZT & 9889.96 & $23,055.87$ \\
\hline \multirow[t]{2}{*}{$c=\varphi / \psi=\mu /(1+\mu)$} & Basic level of the STP multiplier and SSGPO & $\mathrm{KZT} / \mathrm{KZT}$ & 0.74 & 0.49 \\
\hline & The same in percent & $\%$ & 100.00 & 66.74 \\
\hline$c * q=\mu /(1+\mu) * \eta /(1+\eta)$ & Multiplier of socio-political progress in SSGPO & $\mathrm{KZT} / \mathrm{KZT}$ & 0.21 & 0.09 \\
\hline
\end{tabular}

Table 5. Comparative evaluation of the effectiveness of two innovative development options.

\begin{tabular}{|c|c|c|c|c|}
\hline Algorithm & Name of indicators & Unit of meas. & 2028 (option 1) & 2028 (option 2) \\
\hline $\mathrm{NX}=\mathrm{NGDP}+\mathrm{QP}$ & $\begin{array}{l}\text { Scientific and technological potential of SSGPO in terms } \\
\text { of value }\end{array}$ & thousand KZT & $302,054,905.91$ & $302,054,905.91$ \\
\hline$\mu=\mathrm{NGDP} / \mathrm{QP}$ & Efficiency of variable costs excluding salary components & KZT/KZT & 0.98 & 0.98 \\
\hline \multirow[t]{2}{*}{$c=\mathrm{NGDP} / \mathrm{NX}=\mu /(1+\mu)$} & $\begin{array}{l}\text { Multiplier of scientific and technological progress on the } \\
\text { productivity of variable costs excluding salary }\end{array}$ & $\mathrm{KZT} / \mathrm{KZT}$ & 0.49 & 0.49 \\
\hline & The same in percent & $\%$ & 68.39 & 66.74 \\
\hline $\mathrm{NGDP}=\mu /(1+\mu) * \mathrm{NX}$ & $\begin{array}{l}\text { Algorithm for calculating the STP multiplier: } 1 \% \mathrm{NX} \\
\text { provides } \mu /(1+\mu) \% \text { NGDP }\end{array}$ & thousand KZT & $136,140,105.90$ & $149,191,474.19$ \\
\hline $\mathrm{L}$ & Increase in the number of employed & $\operatorname{man}$ & - & -53 \\
\hline$\psi=\mathrm{NX} / \mathrm{L}$ & Increase in labor productivity at full cost & $\mathrm{t} / \mathrm{man}$ & - & +95.5 \\
\hline NPV & Increase in net present value & thousand KZT & & $+926,939.02$ \\
\hline NPV & Increase in net present value & thousand dollars & & $+1,806.40$ \\
\hline
\end{tabular}

by the UN Human Development Index, and which are being transferred to the OECD countries.

\section{Conclusion}

Therefore, the use of the Baizakov's model means that in developing countries the passion for speculative capital ceases to exist, and it is not the subjective propositions of the quantitative theory of money that begin to work, but the objective laws of the qualitative theory of money. In conclusion, the authors note that the theory of preserving the quality of money without applying the gold standard and in the context of globalization and digitalization is called the qualitative theory of money by analogy to the quantity theory of money of M. Friedman.

\section{Founding}

This study was financially supported by grant No. AP05131044 from the scien- 
tific and technical programs and projects of the Ministry of Education and Science of the Republic of Kazakhstan.

\section{Conflicts of Interest}

The authors declare no conflicts of interest regarding the publication of this paper.

\section{References}

[1] Nazarbayev, N.A. (2009) The Keys to the Crisis, Rossiyskaya Gazeta.

[2] Nazarbayev, N.A. (2009) The Fifth Way. Network Edition “Zakon.kz". https://www.zakon.kz/147878-statja-prezidenta-rk-pjatyjj-put.html

[3] Baizakov, S. and Baizakov, N. (2019) The Task of a Three-Fold Economy and the Use of its Model for Comparing the Pace of Development of the Countries. Economic and Statistics, No. 2, 25-29.

[4] Keynes, J.M. (2002) The General Theory of Employment, Interest and Money. Helios ARV.

[5] Friedman, M. (2006) Capitalism and Freedom. New Publishing, 77. http://gtmarket.ru/laboratory/basis/3318

[6] Baizakov, S., et al. (2002) Kazakhstan: Trade and Investment Policy Analysis: Anthology of Works of the TACIS Project in Kazakhstan (EDKZ9902) Comments of the Groups of Local Consultants, under Scientific Ed. of S. Baizakov, Astana, I: Arkaim. 480 p.

[7] Proceedings of the International Conference on Agricultural Trade and Foreign Investment for Sustainable Regional Integration in South Caucasus and Central Asia, Baku, 6-7 September 2018.

[8] Schroeder, K. (2018) China 2030-Implications for Agriculture in Central Asia.

[9] Marx, K. and Engels, F. (2011) Tractate T. 2. 142.

[10] Tleubayev, A. and Bobojonov, I. (2018) The Impact of Russian Food Import Ban on the Dairy Sector of Russia.

[11] Baizakov, S., Dzhunussova, D., Shuneyev, S. and Baizakov, N. (2014) Towards a Methodology of Macroeconomic Analysis and Economic Expertise. IT, No. 1, 4-13.

[12] McConnell, K.L. and Brue, S.L. (1999) Economics Principles, Problems and Policies Trans. from the 13th Edition, $974 \mathrm{p}$.

[13] Sagintayeva, S. and Baizakov, S. (2012) In Search of a Consensus Currency of Regional Integration: Monograph. Astana, $183 \mathrm{p}$.

[14] Sailau, B. and Nauryz, B. (2018) Principles of Further Liberalization of the World Economy. Kostanay, Shapak LLP, Astana, 28 p.

[15] Baizakov, S., Khambar, B. and Baizakov, N. (2018) Economic and Mathematical Foundations of the Digitization of Kazakhstan. Economics and Statistics, No. 3, 18-26. 